\title{
Clozapine improved psychosis without worsening parkinsonism
}

\author{
The Parkinson Study Group. Low-dose clozapine for the treatment of drug-induced psychosis in Parkinson's disease. N Engl J Med \\ 1999 Mar 11;340:757-63.
}

\section{Question}

In patients with Parkinson's disease who have drug induced psychosis, how effective is low dose clozapine (compared with placebo) in improving psychosis without worsening parkinsonism?

\section{Design}

4 week randomised, double blind, placebo controlled trial.

\section{Setting}

6 centres in the US.

\section{Patients}

60 patients (mean age 71 y, 57\% men) who had Parkinson's disease, had been taking antiparkinsonian drugs at a fixed dose for $\geq 7$ days before study entry, and had drug induced psychosis for $\geq 4$ weeks before study entry. Exclusion criteria included receipt of any dopamine blocking drug (within $3 \mathrm{mo}$ ), depot neuroleptic (within $1 \mathrm{y}$ ), previous treatment with clozapine, or a change in antidepressant or anxiolytic drug dose (within $1 \mathrm{mo}$ ); history of leukopenia; any systemic disorder that might contribute to psychosis; severe disease; and dementia severe enough to preclude assessment on the psychiatric test battery. 54 patients (90\%) completed the study.

\section{Intervention}

Patients were stratified by site and age $(<70 v \geq 70 \mathrm{y})$ and allocated to clozapine, $6.25 \mathrm{mg} /$ day $(\mathrm{n}=30)$ or placebo $(\mathrm{n}=30)$. The daily dosage started at $6.25 \mathrm{mg}$ and could be increased or decreased during the next 3 weeks (range 6.25 to $50 \mathrm{mg}$ ).

\section{Main outcome measures}

Change in scores on the Clinical Global Impression Scale (CGIS), the Brief Psychiatric Rating Scale (BPRS), and the Scale for the Assessment of Positive Symptoms (SAPS) for psychosis and the Unified Parkinson's Disease Rating Scale (UPDRS) for parkinsonism.

\section{Main results}

The mean daily dose of clozapine at study end was $24.7 \mathrm{mg}$. Patients who received clozapine improved more than patients who received placebo in all measures of psychosis: decrease in CGIS score $(\mathrm{p}<0.001)$, BPRS score $(\mathrm{p}=0.002)$, modified BPRS score $(\mathrm{p}=0.003)$, and SAPS score $(\mathrm{p}=0.01)$ (table). Parkinsonism was not worsened in either group and the groups did not differ for total UPDRS score $(\mathrm{p}=0.36)$; clozapine had a beneficial effect on tremor $(p=0.02)$ (table). Leukopenia developed in 1 patient during the double blind trial and in another patient during a 3 month follow up safety study necessitating discontinuation of clozapine.

\section{Conclusion}

In patients with Parkinson's disease and psychosis, clozapine, $\leqslant 50 \mathrm{mg}$ /day improved psychosis without worsening parkinsonism.

Clozapine v placebo for decrease in measures of psychosis and parkinsonism at 4 weeks

\begin{tabular}{ll}
\hline Psychosis scales & $\begin{array}{l}\text { Difference in mean } \\
\text { decrease }(95 \% \text { CI)* }\end{array}$ \\
\hline Clinical Global Impression Scale & $1.1(0.4$ to 1.8$)$ \\
Brief Psychiatric Rating Scale & $6.7(2.7$ to 10.7$)$ \\
Modified Brief Psychiatric Rating Scale & $6.1(2.6$ to 9.7$)$ \\
Scale for the Assessment of Positive Symptoms & $8.0(2.5$ to 13.5$)$ \\
Parkinsonism scales & \\
$\quad$ Unified Parkinson's Disease Rating Scale, total score & $2.6(-4.0$ to 9.2$) \dagger$ \\
$\quad$ Unified Parkinson's Disease Rating Scale, tremor score & $1.3(0.1$ to 2.6$)$ \\
\hline
\end{tabular}

*CI calculated from data in article. A positive score indicates that the clozapine group improved more than placebo.

†Not significant.

Sources of funding: in part, Orphan Drug Division of the Food and Drug Administration and the Parkinson Study Group.

For correspondence:Dr Joseph H Friedman, Memorial Hospital of Rhode Island, 111 Brewster Street, Pawtucket, RI 02860, USA.Fax +1 4017293101.

\section{Commentary}

Clozapine's selectivity for limbic, as opposed to striatal, dopamine receptors may explain why it is less likely than typical neuroleptics to produce extrapyramidal side effects. ${ }^{12}$

The Parkinson Study Group have confirmed that, even in patients with Parkinson's disease, clozapine can be used to treat psychosis without making parkinsonism worse. Positive symptoms, as assessed using SAPS, seemed particularly sensitive with clozapine producing a halving of SAPS score from a mean baseline score of 21 (range of possible scores 0-176, higher score indicating more severe psychosis).

The patients had fairly stable psychosis and were presumably on moderately large doses of levodopa. Almost one third were taking pergolide. Thus we can assume that the majority had drug induced psychosis, although this is not entirely clear from the entry criteria. Only 4 patients were on anticholinergics.

The study easily achieved its target of being powerful enough to rule out a clinically significant deterioration in parkinsonism in patients on clozapine. In fact the parkinsonism scores for patients on clozapine improved (mean decrease in parkinsonism score over 4 weeks was 6.4 [SE 2.9]; baseline score was 52.0 measured using the UPDRS, possible range 0-160), and improved more than those on placebo.

Side effects were generally not troublesome, although clozapine was associated with a substantial increase in heart rate (4 beats/min), so care should be taken in those patients with unstable angina.
In the study the clozapine dose was started low $(6.25 \mathrm{mg} / \mathrm{d})$ and was increased slowly (maximum $50 \mathrm{mg} / \mathrm{d}$ ). If the same treatment principles are used, olanzapine (eg, starting dose of $1 \mathrm{mg} / \mathrm{d}$ ) may be an alternative treatment for psychosis in Parkinson's disease, but the patchy evidence to date suggests that olanzapine may be more likely to worsen parkinsonism.

$$
\begin{array}{r}
\text { Simon Fleminger, PhD, MRCP, } \\
\text { MRCPsych } \\
\text { Maudsley Hospital } \\
\text { London, UK }
\end{array}
$$

1 Pilowsky LS, Mulligan RS, Acton PD, et al. Limbic selectivity of clozapine [letter]. Lancet 1997;350:490-1.

2 Kurz M, Hummer M, Oberbauer H, et al. Extrapyramidal side effects of clozapine and haloperidol. Psychopharmacology 1995;118:52-6. 